\title{
Publications
}

Species Conservation: Lessons from Islands edited by Jamieson A. Copsey, Simon A. Black, Jim J. Groombridge and Carl G. Jones (2018) 396 pp., Cambridge University Press, Cambridge, UK. ISBN 978-0-52189939o (hbk), GBP 82.99.

Like indicator species, islands are indicator ecosystems of biodiversity decline and habitat degradation. Isolated, limited in area, and with high endemicity, islands have suffered high rates of species loss. But islands are also beacons of conservation success-in part for the same reasons that make them vulnerable. Isolation and restricted scale potentially make removal of invasive species feasible, and aid the prevention of reinvasions and anchor translocated populations. Species Conservation: Lessons from Islands seeks to encompass a spectrum of conservation relevant frameworks, disciplines and tools, including small and declining population paradigms, invasion biology, conservation genetics, social science, reintroduction biology and project management.

This book departs from the common summary of species focussed woes and hopes, and provides a useful framework for conservation managers. Three chapters are devoted to the social aspects of conservation management, drawing on the rich experiences of the authors. In two chapters Simon Black considers the leadership, organization and management of a recovery team, providing a useful summary of a decision-making framework that should encourage readers to delve further into the extensive literature on structured decision making. Paul Butler and colleagues consider the critical aspect of engaging local communities, which, although here focused on island communities, is a fundamental component of any restoration programme. The sections on the theory of behavioural change will be of interest to anyone working with diverse stakeholder groups.

Other chapters cover more familiar ground but provide insightful reviews of the threats and drivers of species' declines on islands. Two chapters lead by Jim Groombridge look at models of evolution on island systems and how the special features of islands make them speciation engines, and also how this isolation creates closed populations of limited size, vulnerable to stochastic effects. The case is made for long-term genetic monitoring of island population recovery, and a final nod is given to the increasing importance of genomic information. Chapters lead by Alan Tye and John Parkes dovetail nicely, albeit not presented consecutively, by looking at the impacts of invasive species and their eradication. The ability to remove selected invasive species from islands is a game changer, resulting in large islands either on a natural recovery trajectory or a target for species reintroductions. Other contributions flesh out the process and requirements for the management and monitoring of island system recovery.

This volume provides insights into the winning strategies that have resulted in successful island restoration. In many ways islands are tractable test beds for conservation efforts that could also be applied in mainland systems increasingly managed as semi-natural fragments in a sea of human dominated activity. The book meets its brief as outlined by the title: islands are the focus, but the lessons can be widely applied.

PHILIP SEDDON University of Otago, Dunedin, Otago, New Zealand

E-mail philip.seddon@otago.ac.nz

Biology and Conservation of Musteloids edited by David W. Macdonald, Chris Newman and Lauren A. Harrington (2017) 720 pp., Oxford University Press, Oxford, UK. ISBN 978-0-198759812 (pbk), GBP 45.00.

The Biology and Conservation of Musteloids is the third in a trilogy on carnivores produced by Oxford University's Wildlife Conservation Research Unit, the first two focusing on felids and canids. These volumes review and summarize the main aspects of biology, ecology and conservation issues for the three main carnivore groups, and are written by experts in each respective field.

This third volume brings an element of novelty that its predecessors were not able to match: musteloids is not a term you see a great deal in ecological or conservation literature. Many publications about mustelids and their relatives are several decades old, and out of print. The more recent books on this group tend to focus on one or a few closely related species, or consider more species but only address a single topic. The Biology and Conservation of Musteloids fulfills a hitherto neglected need, arguably being the first book to present a synthesis of research conducted on all the species in this enigmatic taxon.

The groups covered are the Mustelidae (mink, polecats, stoats, weasels, martens, otters, badgers and wolverine), Mephitidae (skunks and stink badgers), Procyonidae (raccoons, coatis, kinkajous, olingos, olinguitos, ringtails and cacomistles), and Ailuridae (the red panda Ailurus fulgens). The first half of the book is devoted to summaries of various aspects of musteloid biology, including physiology, ecology, population dynamics, sociality and disease. In addition, two chapters address people's relations with musteloids, and the challenges of researching these species. For much of this section the authors are forced to revert to synthesis and summary, because of the breadth of the subjects addressed and the diversity of the musteloid superfamily. However, they draw on a wide range of examples. The book is well cross-referenced, and uses an accessible and informal writing style that does not debase the science.

The second half is dedicated to species case studies. Most of these focus on North American or European species, with only a few focusing on species in South and Central America and Asia, and none on African musteloids. Africa has the fewest musteloid species of any continent, but given that the greatest musteloid diversity is in Central America, there is some imbalance-a reflection of the fact that most research on musteloids has been conducted in the western hemisphere, with species in tropical regions less studied. Although this book is a celebration of all available research on musteloids, the case study selection indicates how much we still have to learn about many species.

What the case study section represents well is the myriad ways people have interacted with musteloids. These swing between extremes, from significant efforts to protect and restore the last few individuals of some species (blackfooted ferret Mustela nigripes and European mink Mustela lutreola), to efforts to exterminate species that have become rather too successful (the stoat Mustela erminea, weasel Mustela nivalis and ferret Mustela furo in New Zealand, and the common raccoon Procyon lotor). These case studies reflect our varied and often turbulent relationships with these carnivores, and our attempts to overcome aspects of their biology that either predicate or preclude extirpation.

The concluding chapter considers strategies for conservation of musteloids, including appraising the role of musteloids as fundraising ambassadors and umbrella species, their value in terms of ecosystem services, and the potential for effective conservation in differing geopolitical and economic contexts. We are not left with any strong message about how to conserve these species more effectively, but it is uncommon to see musteloids considered as a group through a conservation lens. Although over three-quarters of musteloids are categorized as Least Concern on the 
IUCN Red List, Chapter 7 relates how we have in recent memory witnessed the extinction of a mustelid: the sea mink Neovison macrodon, formerly found along North America's east coast and last recorded in 1894 . The Critically Endangered European mink could become the next mammalian extinction this century, and over half of otter species are threatened.

The Biology and Conservation of Musteloids is a comprehensive synthesis of and much-needed addition to its field. As well as offering a valuable reference for everything we know about musteloid ecology, the book also identifies avenues for further work and research, in both ecology and conservation. I note that the volumes on canids and felids are available as a two-volume set named Biology and Conservation of Wild Carnivores. Hopefully this volume on musteloids will be added to this, to form a trilogy, with musteloids taking their rightful place alongside their larger relatives.

LYDIA MURPHY MKA Ecology Ltd, Cambridge, UK. E-mail murphy.lydia4@googlemail.com

\section{Ecology and Power in the Age of Empire: Europe and the Transformation of the Tropical World by Corey Ross (2017) 496 pp., Oxford University Press, Oxford, UK. ISBN 978-0-199590414 (hbk), GBP 45.0o.}

In 1938 the geographer Carl Ortwin Sauer wrote that European freebooters had overrun the world, believing that their technologies could replace nature. In this lengthy and ambitious book, Corey Ross examines Sauer's conclusion, asking how European institutions, worldviews and technologies affected the natural world in their tropical colonies and, subsequently, how these impacts have shaped today's biosphere. In general terms, we know the answer to this question. But the details and Ross's conclusions merit a careful reading.
The book focuses on the largest imperial expansion in history when, in the late 19th and early 2oth centuries, a small number of European countries extended the territory under their control by 23 million $\mathrm{km}^{2}$-to more than half of the global land surface and a quarter of the world's population. In addition to reshaping politics, social systems and economic activities, the activities of these imperial powers reshaped the forests, grasslands, rivers, coastal plains, soils and mountains. The imperial appetite for natural resources created and shaped new and existing forms of production, from plantations and agricultural fields to mines and forest extraction regimes. As the environmental consequences of these actions were noticed, the imperial powers also moved to conserve the same soil, forests and animals that were being exploited.

But the natural world was not passive in the face of imperial designs, but rather shaped institutions, markets and appetites. Not every crop could be grown everywhere, rivers often rebelled against damming, soils degraded under novel irrigation regimes, and oil was not evenly distributed under the ground. Corey focuses on the interplay of human exploitation and natural constraints, creating what he calls a socioecological framework that 'sought to reorder nature-society arrangements across large parts of the globe' (p. 4). This framework was often insufficiently responsive to local ecologies and institutions and often failed to deliver on expectations.

Ross divides the book into three parts: the environmental impacts of imperial trade networks, with chapters on cotton, cocoa, rubber, tin, copper and oil; conservation and environmental management, with chapters on the politics of nature conservation, forests, agriculture and the environment; and political ecology (really woven throughout the book). There is an excellent concluding chapter on tropical environments and the legacies of empire.

Unlike much of the existing literature, Ross focuses not only on Britains's empire, but also on those of France, Germany, the Netherlands and Belgium. He includes extensive literature, much not in English, bringing welcome diversity and facilitating comparison between the imperial approaches, assumptions and outcomes. The book focuses on the period from the 186 os to when the process of decolonization began between the 1940s and early 1960 .

As Corey points out, the imperial appetite also shaped local institutions and politics and was aided and abetted by local elites, who took the opportunity to strengthen their own power and control. But non-elites were also drawn in, moving and changing their own resource patterns, often under the heavy hand of resource exploiters, but sometimes of their own volition and for their own reasons.

One of the premises upon which European countries based their imperial legitimacy was that their mastery of more advanced technology - and thus a claimed mastery of natureallowed, and even compelled, these countries to bring so-called civilization to the lands they claimed. The approaches to framing ecological problems as ones that European technologies could solve strengthened the authority of technical experts over the local knowledge systems of indigenous communities and led to '...the equally prevalent sense of overconfidence in the ability of scientists and modern states to manage ecosystems on a 'rational' and sustainable basis' (p. 418).

The web of trade and exploitation woven by European imperial powers for their own hegemonic reasons is one of the legacies Ross showcases. This web long preceded the study of 'telecoupling'-distant connections of human and natural systems-that is in vogue nowdays. Reading this book is an important task for many of us who have forgotten how many of the environmental problems we are currently facing were, and continue to be, shaped by the legacies of imperialism. Understanding this history will help us shape the future.

KENT H. REDFORD Archipelago Consulting,

Portland, Maine, USA

E-mail redfordkh@gmail.com 